\title{
A Review on Methods to Reduce Weight and to Increase Efficiency of Electric Motors Using Lightweight Materials, Novel Manufacturing Processes, Magnetic Materials and Cooling Methods
}

\author{
Darius Gnanaraj Solomon ${ }^{1 *}$, Adriana Greco ${ }^{3}$, Claudia Masselli ${ }^{4}$, Edison Gundabattini ${ }^{1}$, Raja Singh Rassiah ${ }^{2}$, Ravi \\ Kuppan $^{2}$
}

${ }^{1}$ School of Mechanical Engineering, VIT, Vellore 632014, India

${ }^{2}$ School of Electrical Engineering, VIT, Vellore 632014, India

${ }^{3}$ Department of Industrial Engineering, University of Naples Federico II, Naples 80131, Italy

${ }^{4}$ Department of Industrial Engineering, University of Salerno, Fisciano (SA) 84084, Italy

Corresponding Author Email: dariusgnanaraj.s@ vit.ac.in

https://doi.org/10.18280/acsm.440101

Received: 20 October 2019

Accepted: 3 December 2019

\section{Keywords:}

electric motor, lightweight, magnetic materials, efficiency, cooling

\begin{abstract}
The electric motor is the mechanism that transforms electrical energy into mechanical energy. Nowadays, electric motors are the cause of a considerable share of the use of electricity and therefore of the energy consumptions ( $70 \%$ in the industrial sector and 25 $30 \%$ in the tertiary sector). Faced with ever-increasing energy demand and with a view to adhering to the all-over-the world imperative of adopting measures to reduce energy consumption in all the involved sectors, the use of efficiency enhanced electric motors is required. Generally, the efficiency of an electric motor depends on the type of motor, the size of the motor, the utilization factor, but also on the quality and quantity of the materials employed. Therefore, from all these aspects the need of using energy and costefficient components for developing electric motors arises. This review paper aims to draw a general framework on the methods of increasing efficiency and of reducing weight of the electric motors.
\end{abstract}

\section{INTRODUCTION}

Basing on an exponentially growing global energy demand, predominantly satisfied by the use of fossil fuels, that are present in limited quantities and with greater responsibilities in the emissions of climate-altering gases in the atmosphere, it is necessary to intervene on the levels and methods of consumption of energy resources, in order to guarantee a balanced and lasting development and mitigate the ongoing climate change processes. The World Bank Open Data claims that the worldwide consumption of per capita energy has risen from $1400 \mathrm{kWh}$ in 1975 to $3200 \mathrm{kWh}$ in our days [1]. This hunger for energy touches all the sectors. Consequently, allover the world countries are adopting measures to reduce energy consumption in all the involved sectors. As an example, the European Union in March 2007 set three specific goals to be achieved for the 2020. Among these objectives, there is also a $20 \%$ progressive reduction in energy consumption. In order to achieve this goal, improving efficiency in the end uses of energy is one of the roads to be pursued [2].

As shown in Figure 1, currently electric motors represent a considerable amount of the use of electricity, and therefore of the energy consumptions in the industrial sector (74\%), but also in the tertiary sector $(26 \%)$ being employed in many plants of service (pumping systems, production and distribution of compressed air, ventilation systems, etc.). Every year, ten lakhs electric motors are produced in the world. The EU Regulation 640/2009 of the European Commission [3] issued in 2009, lays down rules for the application of Directive 2005/32/EC of the European Parliament and of the Council regarding the eco-compatible design of electric motors [4]. Therefore, the use of Efficiency Enhanced Electric Motors (EEEM) [5] is highly cost-effective, even more considering that in general the useful life of the motor. Generally, the efficiency of an electric motor depends on the type of motor, the size of the motor, the utilization factor, but also on the quality and quantity of the materials employed.

From all these aspects, the need of using energy and costefficient components for developing electric motors arises. Among them, electromagnetic components of Soft Magnetic Composite (SMC) materials [6] play a key role in this context, stemming the possibility of manufacturing portable, costefficient and lightweight sustainable electric motors and inductors compared to the conventional designs.

There are many applications for lightweight electric motors. The term composite motors [7] derives from the concept of composite materials, the combination of two or more different elements that, when combined, create a material with unique characteristics that are not related to the individual component. Composite motors are based on distinct composite materials; the application of them in the system led to the patents of many EEEM. Most of them are characterized by various benefits such as singular design, enhanced heat transfer and better performances. A further advantage of the composite fiber construction, in addition to the high freedom in design, is the option of integrating function. As compared with lightweight metal materials, fiber-reinforced plastics also offer some more degrees of freedom, by means of which the material and component characteristics may be influenced. The types of the matrix and of the fibers have influence on the characteristics, 
as well as their proportion to each other and the orientation of the fibers within the component. Weight, structural durability and the costs and complexities of the manufacturing process may be tailored to the requirements of the individual application.

This review paper aims to draw a general framework on the methods of increasing efficiency and of reducing weight of the electric motors. The applications of lightweight materials and novel manufacturing processes are discussed as methods for reducing the weight. Moreover, a special focus is made on magnetic materials and cooling methods for increasing efficiency of electric motors.

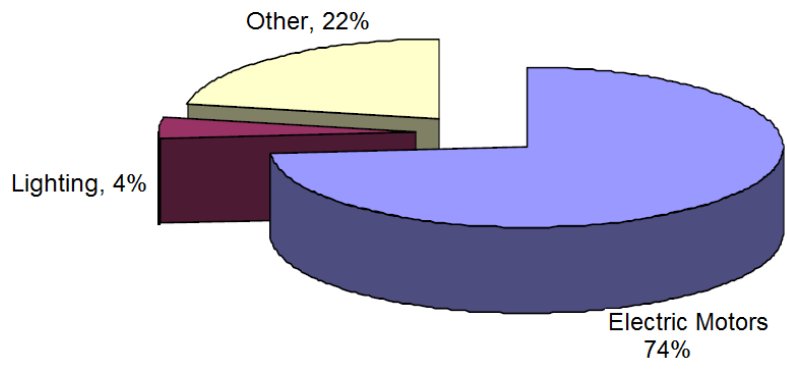

Figure 1. Main electricity consumption in the industrial sector

\section{ELECTRIC MOTORS: GENERALITIES AND CLASSIFICATIONS}

In this section the general operating principles of the electric motors are introduced.

\subsection{Generalities}

An electric motor is an electromechanical energy conversion device which converts electrical energy to mechanical energy in the form of linear or rotational motion. The electric motors' operating theory depends primarily on the interaction of the magnetic and electrical field. Many are the parameters usable for comparing electric motors: torque, power density, construction, basic operating principle, loss factors, dynamic response, and efficiency. The last one is the most significant one. The causes of low efficiency of electric motors can be mainly attributed to the following factors:

- inappropriate sizing;

- low electrical efficiency of the engines used;

- low mechanical efficiency of the end user (pumps, fans, compressors, etc.);

- absence of speed control systems;

- poor or even non-existent maintenance.

To maximize the energy performances of electric motors, it is essential to minimize the losses arising from the various transformations of energy, occurring in the operation of these machines. As a matter of fact, in an electric motor, energy transforms itself from electric into electromagnetic and then its further changes in mechanical energy. Efficiency Enhanced Electric Motors differ from traditional electric ones because in the former the losses are minimized. As a matter of fact, in the traditional motors the losses are mainly caused by:

- mechanical losses due to friction losses and windage losses (in bearings and brushes and ventilation);

- losses in the vacuum iron (proportionate to the voltage square), consisting of losses due to hysteresis of scattered energy involved with changes in flow direction and losses due to Eddy currents caused by circulating currents within the core and caused by flow changes;

- losses due to the Joule effect (proportional to the current square).

In Figure 2, the classes of efficiency of the electric motors are shown comparing the efficiency with the nominal power. For every class the minimum efficiency value is established. Furthermore, the curves of efficiency with respect to nominal power for 2- and 4- poles electric motors are reported. The traditional electric motors belong to the class efficiency 3 whereas EEEM to the classes 1 and 2, if they are respectively 4- or 2- poles based. Most of the engine fleet present in the production and commercial plants falls in the efficiency class number 3 . It would be appropriate to proceed with a gradual diffusion and introduction in the production cycles of highefficiency engines.

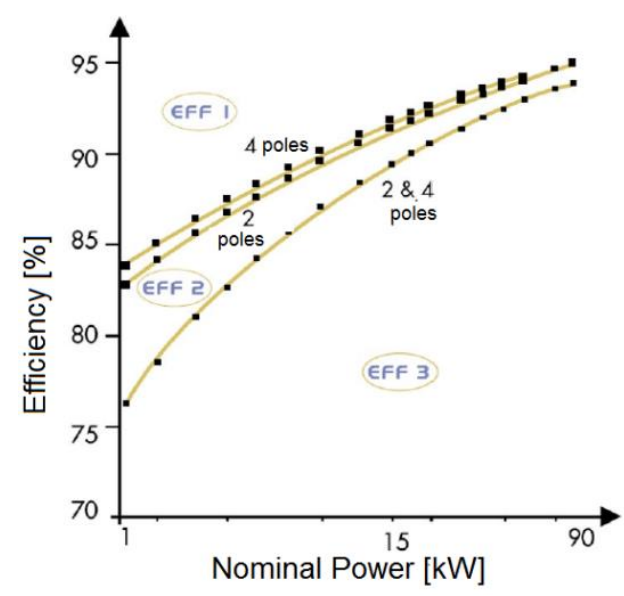

Figure 2. Classes of efficiency for electric motors

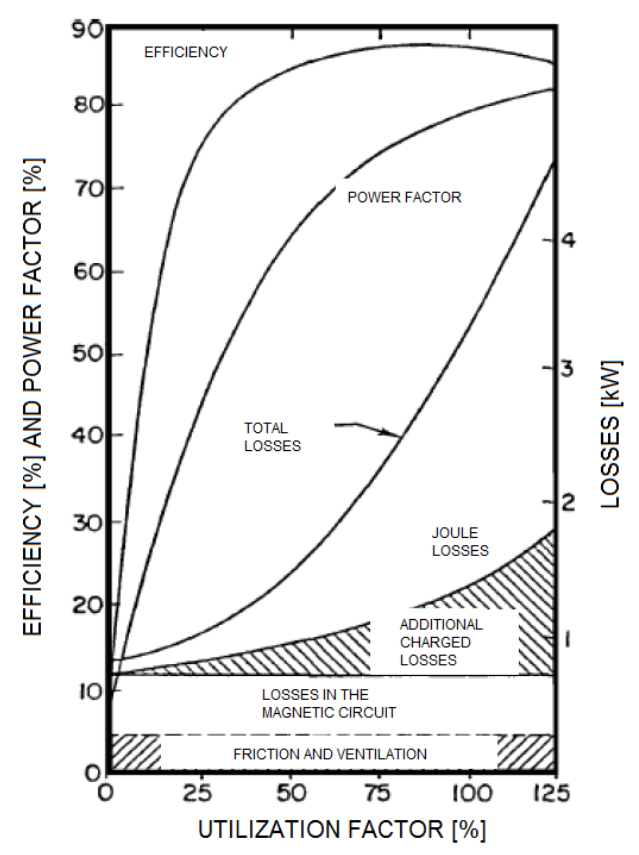

Figure 3. The efficiency, the power factor and the losses (both total and singular addends) trends as a function of the utilization factor of an electric motor

In Figure 3, some significant trends for an electric motor are reported as a function of the utilization factor: the efficiency, the power factor and the losses (both total and singular 
addends). Generally, the efficiency of a motor depends on the working point and, specifically, it decreases as the utilization factor decreases; when this is less than 0.5-0.6 the decrease is particularly drastic. With reference to the motor size, the efficiency increases with the increasing of the nominal power

Several types of electric motors are now available and they are more adaptable than ever before.

\subsection{Classification}

In Figure 4, a general classification of the existing types of electric motors is proposed. The electric motors are mainly classified into two types: Alternating-Current (AC) or DirectCurrent (DC) motors. As the name suggests, they take alternating or direct current as an input to be converted into mechanical power.

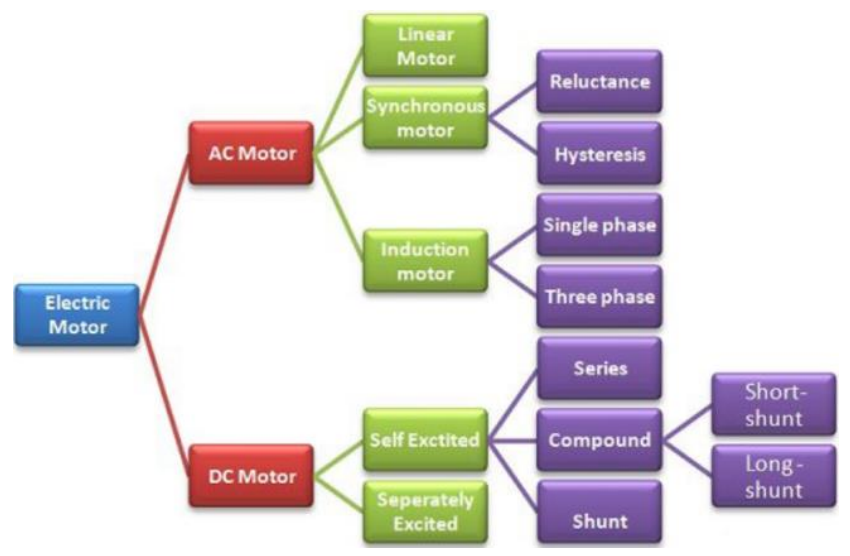

Figure 4. Classification of electric motors

\subsubsection{AC motors}

The AC motors can be further divided as:

a. induction (or asynchronous) motors;

b. synchronous motors;

c. linear motors.

a. Induction or asynchronous motor is the machine that never runs at synchronous speed. This motor uses the phenomenon of electromagnetic induction to convert electrical power into mechanical power. Two types of induction motors are there according to rotor construction: the squirrel cage induction motor and the phase wound induction motor $[8,9]$. The motor that involves a rotor type squirrel cage is known as an induction motor for the squirrel cage. The rotor of the squirrel cage eliminates the humming sound and the magnetic lock of the rotor. The rotor is a phase wound induction motor that has slip ring and brushes for adding external circuit to improve the performance of the motor, also known as the slip ring rotor.

The induction motor is separated into two forms by the phases. There are; single-phase induction motor which transforms two-phase AC electrical power into mechanical power using the principle of electromagnetic induction, similarly, the 3-phase induction motor converts three phase AC electrical energy to mechanical power. In general, induction motor (IM) drives present some drawbacks arising from the electric propulsion and extra-high voltage. These are mainly identified as high losses, low efficiency and power factor, small utilization coefficient of the inverter; their incidences on the performances of the motor become more serious for the high speeds, large powers of the motors.
Fortunately, these drawbacks are considered in order to overcome those issues, also for the electric vehicles' applications [10-12]. New control strategies were proposed to improve the efficiency of induction motors $[13,14]$. Some of the implemented techniques are specifically aimed at applications for hybrid electric vehicles (HEVs) [15, 16], which is a step forward compared to the prior art [17]. Jiang et al. suggested the use of multi-phase pole-changing induction motors, particularly for traction operation, to stretch the constant-power area without increasing the size of the motor [18]. Other novelties lay in multiphase induction motors, i.e. based on machines having more than three phases; they are specially addressed to many modern applications, such as vehicles and naval propulsion systems or the electric aircraft [19-21]. A fundamental principle is the possibility of independently controlling the spatial harmonic permanent magnet machines and the analysis with several methods of the induction machines faults [22-26].

b. The machine is known as the synchronous motor, which changes the alternating current to mechanical power at the desired frequency. The speed of the motor is related to the input supply frequency in the synchronous motor. The synchronous speed is gauged with respect to the magnetic field rotation, and it changes depending on the frequency and poles of the motor. Two types of synchronous motors are there: switched reluctance and hysteresis motors (also called synchronous permanent magnet motors).

The Switched Reluctance Motor (SRM) is the synchronous motor whose starting process is comparable to the one proper to an IM and runs like a synchronous motor. The stator of SRM has concentrated coils. The SRM is a doubly salient type of motor with phase coils placed diametrically opposite around stator poles. The rotor is a piece of steel and its shape forms poles, which have no permanent magnets or windings. The main advantage of SRM is, there is no need of the excitation for rotor. Other advantages are low cost, low maintenance, simple control, more reliability compared to other machines. Due to more torque ripples, noise, vibrations and saturation these machines are limited [27-29]. Figure 5 illustrates the current entry ports in a three-phase switched reluctance motor coil.

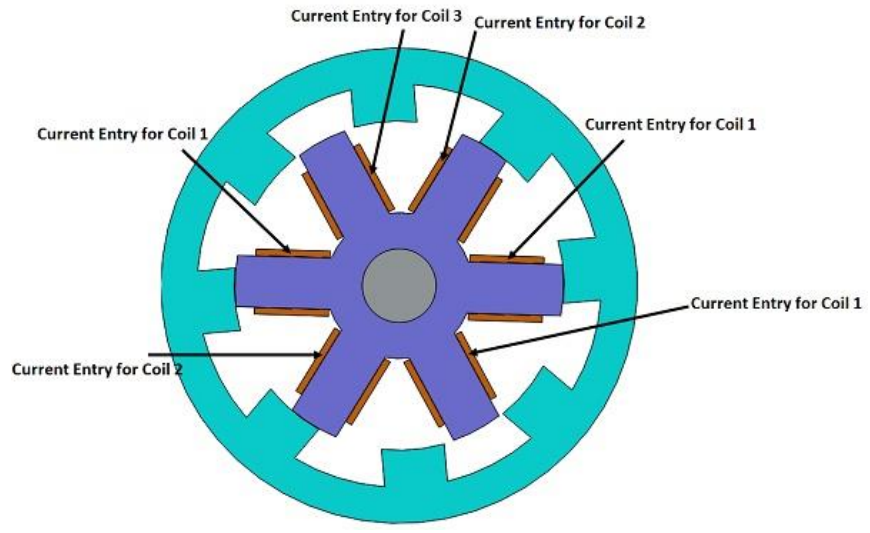

Figure 5. The entry of the current in three-phase switched reluctance motor coil

The hysteresis motor is the kind of synchronous motor that has a uniform air gap and has no DC excitation device. It mounts Permanent Magnets (PM) and the torque in the motor is developed by the eddy current and hysteresis of the motor. In this type of motors, because they are synchronous, motor 
stator and rotor are rotating at same speed. Most of the hybrid electric vehicles are predominantly using PM Synchronous Motor: these motors present less overall weight, less volume with high power density, better efficiency and less heat loss. Due to lesser field weakening capacity, these machines have a limited constant-power region due to the presence of the PM field [30]. However, the efficiency may decrease at a highspeed range due to the risk of PM demagnetization [31-33].

c. A linear motor produces a linear force along the length instead of torque (rotation). Linear motors are not necessarily straight. The active section of the linear motor is characteristically terminated, while traditional motors are arranged in a loop. They are designed with a passive plate (rotor) on side of the airgap and active 3-phase winding (stator) on the other side.

\subsubsection{DC motors}

A machine that transmits DC electrical power to mechanical power is understood as DC motor and its operating principle depends on the practical phenomenon in which a force is exerted on it and torque is developed when a conductor carrying current is placed in a magnetic field. The DC motors are classified into two types:

- $\quad$ the self-excited motors;

- the separately-excited motor.

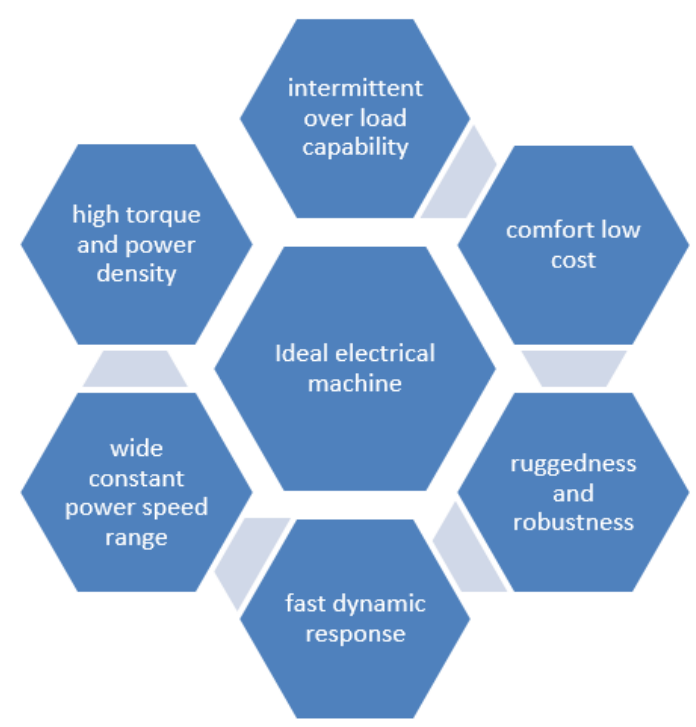

Figure 6. Criteria for developing an ideal electric motor

In the separately excited DC motor, the independent DC source excites the DC field winding. The self-excited DC motor is further categorized into three forms by the field winding. They are the series motor, shunt motor, and compound motor. The motor is known as the shunt motor in which field winding and armature are kept parallel. The connection between the field winding and the motor armature are in series in the series motor. The DC motor is known as the compound wound motor, in which the field winding has both the parallel and series connections. The compound wound motor is classified as (i) a short and (ii) long shunt motor. If the shunt field winding is parallel to a motor armature and not the series field, it is named as the short shunt compound motor. Similarly, the motor is named as the long shunt motor, if the field winding is parallel to both the armature and the series field winding. In most of the cases, a DC motor can operate between 96 and 192 volts. In addition, DC motor has high torque and low cost. It is also possible to divide DC motors into three categories: Brushed DC motor, Brushless DC motor and stepper motor. In electric vehicles, brushed DC motors are widely used to retract, position and extend side windows that are electrically powered. Because of their low cost, these motors are ideal for many applications. However, because of their continued contact, the commutators and brushes tend to wear relatively quickly, leading to regular maintenance and eventual replacement. DC motor drives have a voluminous structure, lower efficiency, lower reliability, and high maintenance requirements, primarily due to commutator and brushes, even though slippery contact made notable progress [34]. In recent times, the researchers have been focusing on electric motors for heavy duty electric vehicles. It mainly targets on requirements such as maximum efficiency, higher power density, high specific torque, lesser noise, and cost.

The specifications for an electric machine (EM) are summarized in Figure 6.

\section{METHODS TO REDUCE WEIGHT OF ELECTRIC MOTORS}

The present paper aims to focus mainly on the electric motors devoted to the application in electric vehicles. The Electric vehicles use AC permanent magnet synchronous \& asynchronous machines and electrically excited synchronous machines. On the other hand, reluctance or DC motors are not so commonly employed. The automotive industry devotes particularly the interest on EEEM [35]. To pursuit this aim it is necessary to improve all the aspect concerning the development of an electric motor: from the design to the efficient production of the components with optimized materials. All these factors constitute essential elements to reduce power dissipation of the EM and therefore to enhance the efficiency of the electric motor.

In the following subsections, a focus on both the aspects concerting the realization of an Enhanced Efficiency Electric Motor will be provided: the usage of lightweight materials and novel manufacturing processes.

\subsection{Lightweight materials}

The first factor inherent to the realization of an enhanced efficiency electric motor is the integration of lightweight technology to substitute the older-technology related components, with less heavy materials. Light weighting helps us to achieve these goals. We have only a few technologies for mass production of electric motors for electric vehicles. Braking technology will depend on regenerative technology, smart cars and autonomous vehicles. As an example, the use of fiber-reinforced plastics, shows a higher potential to reduce the weight of electric motors and also increases the electrical and mechanical properties of driving systems.

Phenolic composite materials have electrical insulation and resistance to corrosion. There is also a convenient way to replace multiple metal parts with a single plastic component in molded form. Although these materials have potential for many industrial drive applications, they are used mainly in automotive components. Most of the electric motor engineers know that phenolic composite materials offer excellent electrical insulation in commutators and brush holders [36]. There is great interest in developing and testing lightweight materials as substitutes of heavier materials in the electric 
motors as evidenced by the updated inherent state of the art. The Institute of Production Science [37] is, in fact, investigating solutions for the use of fiber-reinforced plastics in the electric motor. The rotor, stator, and housing were designed to be developed with integrated cooling. The Vehicle System Technology Institute (FAST) designs fiber composite components. The use of modern simulation tools ensures that the operating requirements are met by these components.

Koch et al. [38] have proposed two methods to produce light weight electric motor rotors. Stainless steel and carbon reinforced plastics are used to make the CFRP shaft. Dry filament winding is combined with centrifugal casting to produce the shaft.

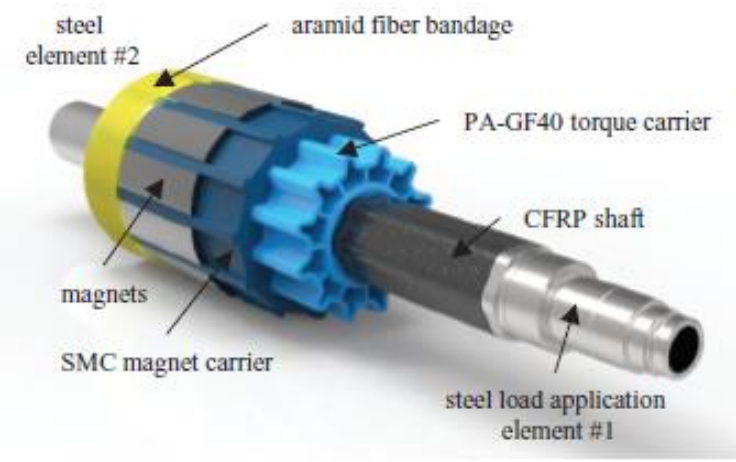

Figure 7. Design of a lightweight permanent magnet rotor [38]

For replacing electrical sheets, the second method uses soft magnetic compounds (SMC, iron-filled polyamide compound). These parts are produced using injection molding process. A prototype was made for the hybrid shaft assembly using the SMC. The development of a lightweight permanent magnet rotor is illustrated in Figure 7. The project partners of Fraunhofer et al. [39] made engine and housing using polymers and dissipated heat near the source. Polymer housings are lightweight and simple compared to aluminum housings. Since near net-shape products are made, it results in weight and cost savings. Polymer materials with low conductivity are able to replace metals.

The Institute of Production Science is exploring strategies for the use of fiber-reinforced plastics in the electric motor under ProLeMo [40]. These scientists have developed the process chain that a demonstrator needs to produce. The rotor, stator and housing were designed to be manufactured with integrated cooling. Using aluminum matrix composites (AMCs) can improve electric motor efficiency and performance [41]. Through a collaborative project with AMC specialists, Alvant [41] achieved a 40 percent reduction in rotor weight while increasing the power-to-inertia potential of the rotor and maintaining the rigidity of the rotor. However, the number of assembly line pieces has been reduced, which can lead to a shorter production period. Efficiency and responsiveness of the motor were increased, and thermal resistance was enhanced. It is reported in the paper [42] that making electric cars lighter means reducing the weight of the engine. Polymer materials reinforced with fiber will help the designers to achieve this. Researchers at the Fraunhofer Karlsruhe develop a new cooling concept which permits the use polymers for making the motor housing. Power density and efficiency of motors increase apart from the new cooling concept. Electric motor and the battery are important for electrical drives. High power density, a lightweight configuration and high efficiency levels are important key concepts.

In their patents [43], Donner et al. used a thermally conducting, lightweight FRP for electric motor housing. According to this design, a new housing system for electric motors is made. CFRP materials are used for making the housing with metal pins for improving the thermal conductivity across the thickness apart from cooling liquid jackets. Thus, a heat dissipating housing is made through this novel technology. If appropriately designed, the use of FiberReinforced Plastics (FRP) enables higher stiffness, enhanced material damping properties and higher damage tolerance with lower weights [44]. In the area where the electric motor and the fiber composite wheel (motor adaptor flange) are connected, a higher natural frequency can be achieved, with enhanced damping properties, the use of high-modulus fibers, which, in addition to the great lightweight potential, enables low noise emission to be achieved.

\subsection{Novel manufacturing processes}

Manufacturing processes face several challenges while using lightweight materials.

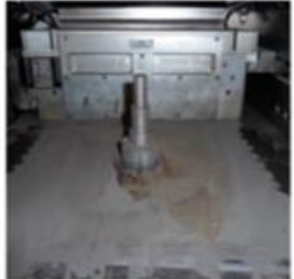

(a)

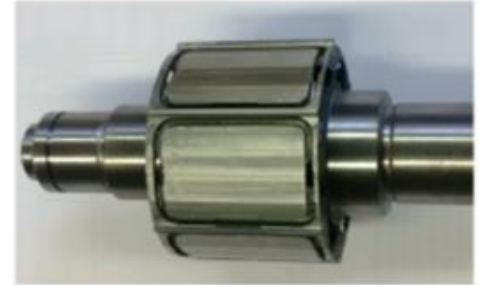

(b)
Figure 8. Additive manufacturing process (a) rotor active part and (b) shaft

The popular worldwide strategy is to slowly expand the number of electric vehicles in use, resulting in increased demand for electrical traction systems, while promoting the economic importance of manufacturing processes [45]. Alternative approaches are presented to produce electric motors, consisting of rotor, stator and housing. Among the emerging technologies dedicated to this dream, additive manufacturing is a promising technique for electric motor production and provides many potential benefits such as high power density and reduced weight, modern electrical model, cost reduction, electronic integration [46]. The Belgian startup Magnax produced a compact, lightweight, ultra-high-power, axial flux electric motor in 2018 [47]. Metal additive manufacturing make it possible to build electrical machine parts layer by layer. Complex 3-D parts are made by fusion using a high-power laser beam as shown in Figure 8. This technology opens up new design possibilities for electrical machine parts [48].

Structures using conductive polymer composites are made through 3D printing techniques. This technique adds tolerability of size and shape of objects produced. An easy method for preparing conductive polymer-based powder is presented: the nano sheets are made by attaching commercial polymer powder on graphene oxide nano sheets. These sheets are electrically conductive, and $3 \mathrm{D}$ printing is used for finishing operations. This method uses polymer particles covered with carbon nanoparticles which are used for printing electrically conductive parts using 3D printing technique. 
Characterization of mechanical, electrical and chemical properties is carried out. The first prototype of a motor assembled by parts made through $3 \mathrm{D}$ printing without any metal part is reported by De Leon et al. [49].

Zhang et al. [50] presented a cost-efficient manufacturing technology for an electric motor shaft rotating at $12000 \mathrm{rpm}$ with $10 \mathrm{~kW}$ peak power and $28 \mathrm{Nm}$ peak torque. Material selection is based on strength and cost. The utilization of a material with high strength could increase the unit price but the global cost may be less. Sometimes, it is more beneficial to select an expensive material which can be shaped using a low-cost manufacturing process which may be beneficial. Such balancing between material cost and process should be considered for these types of solutions. Chai et al. [51] decreased weight of their electric motor by $25 \%$ by removing useless core from the rotor. The power density of the motor was improved by $57 \%$ compared to prototype motor. They have experimentally validated it in-wheel motor, successfully.

Ruff et al. [52] stated that the top-down and bottom-up processes are two ways of producing components and products. There are advantages and disadvantages for each operation. In a series of steps, the bottom-up approach was chosen to create electromagnetic devices using nanoscale materials. The development of an electric motor using nanoscale materials to achieve light weight is explained. Motor engineering is ongoing work, but it defines various processes and outcomes. In the embodiments described in the patent specification [53], an electric motor stator has an external ring member made of resin material and supported by stator caps and a flanged internal composite ring member made of resin material receiving a steel band from a frame. Inside the steel band are mounted laminations and coil windings and the steel band, laminations and coil windings are encapsulated in an outer wrap of resin material. A rotor arrangement consists of a steel hub surrounded by a disk-shaped member made of resin material and connected by radial arms with internal and external rings. The peripheral surface of the disk-shaped member is surrounded by a non-ferromagnetic steel band and laminations and magnets or coil windings are placed on the band and encapsulated by an outer resin material wrap.

The Chemnitz University of Technology [54] achieved the first 3D printed in the world with an electric motor made of ceramic, copper and iron. They printed an entire electric motor, as shown in Figure 9. Ceramic and metallic pastes are extruded layer by layer alternatively and sintered together.

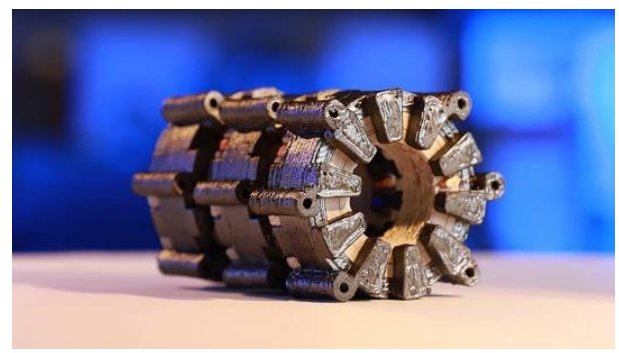

Figure 9. The 3D printed electric motor of the Chemnitz University of Technology [54]

\section{METHODS TO INCREASE EFFICIENCY OF ELECTRIC MOTOR}

In the following sections, the techniques to improve the efficiency of the electric motor will be illustrated.

\subsection{Magnetic materials}

Magnetic materials are nowadays used in many applications $[55,56]$ : among them the most commons are as refrigerants of solid-state magnetic refrigeration [57-59] and to increase the efficiency of the electric motors. One of the ways to increase electric motor efficiency is achieved by replacing traditional methods by Soft Magnetic Composite (SMC) or iron powder materials. The main advantage in employing SMC materials is the cost-effective ratio and by more eco-friendly production processes; the peculiarity is the minimum waste of material thanks to the powder metallurgical techniques, which are $50 \%$ more efficient than the conventional manufacturing processes. With the employment of such materials, a restyling of the design of the magnetic circuit is needed to make up the magnetic properties of composite materials. The interventions that can be made are the following: design the magnetic circuit characterized by a shorter magnetic flux path than the synchronous electric motors made of laminated magnetic circuits; expand the cross section; avoid the local material saturation, utilize the distribution of the paths of magnetic flux in all 3 directions of the magnetic circuit. Composite materials have the following benefit: higher electrical resistance resulting in lower current losses from Eddy [60].

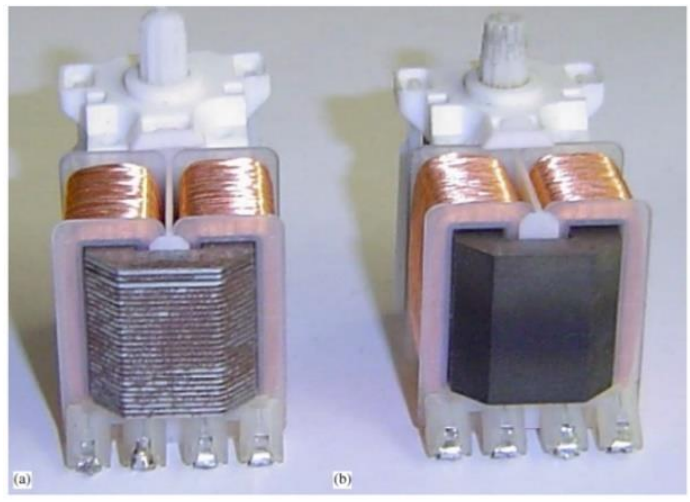

Figure 10. The stator of a synchronous electric motor made of (a) laminated silicon iron sheets, (b) soft magnetic compounds [63]

The first application of SMC made of iron powers was realized in 1990 as reported by Kordecki and Weglinski [61]. In 1992, Jansson studied the production processes and properties of Soft Magnetic Composite materials for applications for AC synchronous electric motors [62]. Since then, SMC materials gained a lot of attention and became more attractive for being employed in electric motors and many researches groups started working on it. In 2006, Hamler et al. [63] introduced an interesting study in which the magnetic condition of synchronous permanent magnet rotor electric motor whose stator core was a combination of 2 different materials. In the first case, the stator consisted of sheets of laminated silicon iron and in the second case, the motor was analyzed with the stator made of SMC, as shown in Figure 10 (a) and (b). The object of the investigation was to research the effect of stator materials on the magnetic conditions of SEM, mechanical and electrical characteristics, and production costs. The analysis of the magnetic conditions was perpetuated by the help of a 3D FEM numerical model, experimentally validated. He concluded that SMC is a viable alternative to condensed magnetic product sheets made of iron despite the lower magnetic properties. Indeed, the employment of SMC 
material having isotropy abbreviates the paths of the magnetic flux and to balance the more reduced magnetic properties of the former.

Widmer et al. [64] reported that Neodymium Iron Boron $(\mathrm{NdFeB})$ is used in many of the electric vehicles today. These motors offer high torque, high efficiency, small size but they are expensive. Table 1 presents the comparison of three different technologies for developing electric motor. Switched reluctance motors and low-cost ferrites can replace $\mathrm{NdFeB}$ motors in future since they are of less cost and sustainable. De Gennaro et al. [65] compared the relationship of the efficiency of the following types of electric motors with their torque density (Nm/L): SRM (Switched Reluctance Machine), WFFSM (Wound Field Flux Switched Machine), Ferrite PMFSM (Permanent Magnet Flux Switched machine), Ferrite PMaSynRM (Permanent Magnet assisted Synchronous Reluctance Machine), Ferrite PMSM (Permanent Magnet Synchronous Machine), SCIM (Squirrel Cage Induction Machine) and NdFeB-IPMSM (Neodymum Iron BoronInterior Permanent Magnet Synchronous Machine) and benchmarked the electric machine made of Ferrite PMaSynRM. It produced $75 \mathrm{~kW}$ at $4000 \mathrm{rpm}$ with a torque density of $32 \mathrm{Nm} / \mathrm{L}$ and an efficiency of $96 \%$.

Table 1. Comparison of electric motor technologies which reduce or eliminate rare earth magnets [64]

\begin{tabular}{cccc}
\hline $\begin{array}{c}\text { Motor } \\
\text { Technology }\end{array}$ & $\begin{array}{c}\text { Reduced } \\
\text { NdFeB } \\
\text { magnet }\end{array}$ & $\begin{array}{c}\text { Ferrite } \\
\text { Permanent } \\
\text { Magnet }\end{array}$ & $\begin{array}{c}\text { Switched } \\
\text { Reluctance }\end{array}$ \\
\hline $\begin{array}{c}\text { Peak Power } \\
\text { Peak Efficiency }\end{array}$ & $\begin{array}{c}90 \mathrm{~kW} \\
80 \%\end{array}$ & $\begin{array}{c}96 \% \\
\mathrm{~kW}\end{array}$ & $75 \mathrm{~kW}$ \\
$\begin{array}{c}\text { Active material } \\
\text { cost per kW }\end{array}$ & $\$ 2.78 / \mathrm{kW}$ & $\$ 1.93 / \mathrm{kW}$ & $\$ 1.57 / \mathrm{kW}$ \\
Torque Density & $15 \mathrm{~N}-\mathrm{m} / \mathrm{kg}$ & $11 \mathrm{~N}-\mathrm{m} / \mathrm{kg}$ & $15 \mathrm{~N}-\mathrm{m} / \mathrm{kg}$ \\
\hline
\end{tabular}

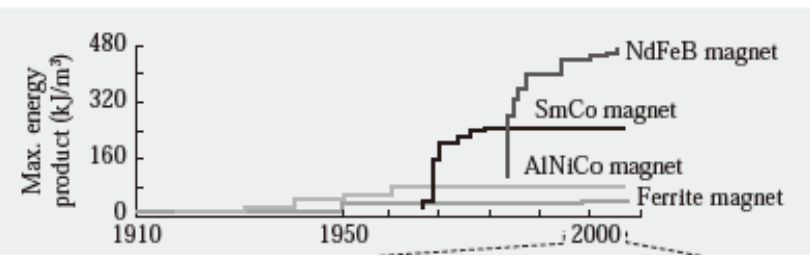

Figure 11. Advances in motors attributed to magnets of rare earth [64]. The invention of neodymium magnet made a major advance in motor performance

Mikami et al. [66] reported a progressive improvement of the magnet-energy material from ferrite through alnico and samarium-cobalt. After their invention, the use of neodymium magnets (the strongest type of magnet) increased rapidly. Smaller coil end sizes were achieved by adopting concentrated windings for the stator after the arrival of neodymium magnets. Figure 11 shows the advances in motors due to rare earth magnets and Figure 12 shows the comparison of size of original 5 HP motors with current Induction motors with new prototype.

In 2016, Ferraris et al. [67] proposed to the community, as shown in Figure 13, a SMC manufactured by mixing phenolic resin and iron powders in different $\%$ ages of weight and mold pressure. Mechanical and magnetic properties of the new compounds were evaluated and then compared with the ones of commercial SMC. Figure 14 reports a comparison between the magnetic properties of the phenolic-mixing SMC and the base SMC [67]. They found that, reduction of the amount of resin enhances the magnetic properties; the results obtained with 0.2 percent of phenolic resin are acceptable. The properties of this combination match with the properties of commercial products.

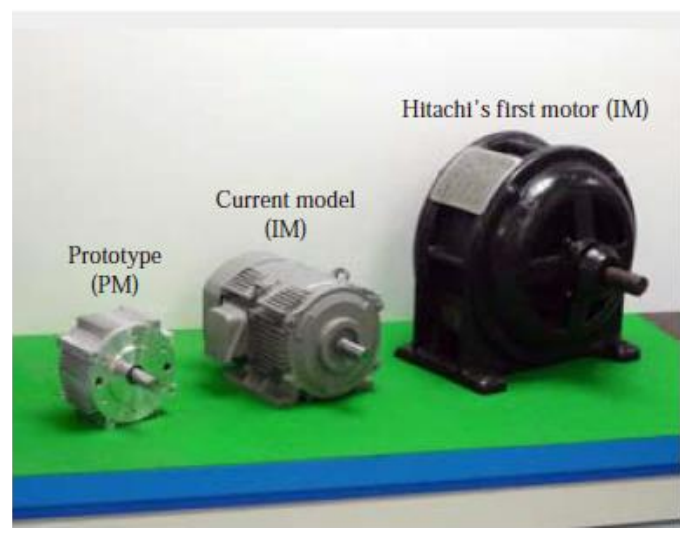

Figure 12. Comparison of original 5-HP motor, current production model and new prototype [66]. The body of the prototype motor is only one-fifteenth the size of Hitachi original motor and one-third of the current Induction motor

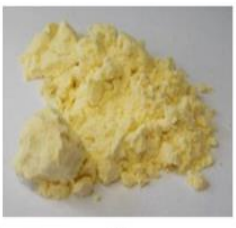

a)

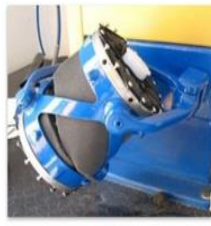

b)

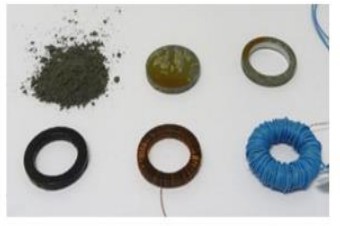

c)
Figure 13. (a) phenolic resin, (b) turbula mixer, (c) samples realization sequence [67]

Ferraris et al. [68] studied the influence of particle size on the losses of SMC with $0.2 \%$ of phenolic resin. The results revealed that the larger the particles, the lower the magnetic and energy performances whereas the smaller they are, better is the enhancement, especially for increasing frequencies. The mechanical strength is dependent on fractions matching the medium and large particle sizes. Hybrid Magnetic Composites (HMC) [69-71] made of a mixture of soft and hard magnetic powder materials having a polymer binder provides mechanical strength and they are promising materials. HMCs are very small manipulative permanent magnets and can be used to replace AlNiCo and ferrite magnets. HMC is primarily devoted to the application of sensors. Soft magnetic composite materials are manufactured using iron powder particles coated with an insulating layer. Powder metallurgy is used to form these powders into complex shapes [72], allowing the design of 3D magnetic circuits. Höganäs offers design services using a range of SMC materials with unique three-dimensional flux properties. These products provide unique values for a variety of automotive and industrial applications. The main advantages for both production processes and motor development for SMC solutions are:

- slim layout - both weight and part size can be reduced;

- high performance - suitable for highest output requirements;

- great cost efficiency - slim models need less material and enable efficient net production eliminating waste and finishing operations. 


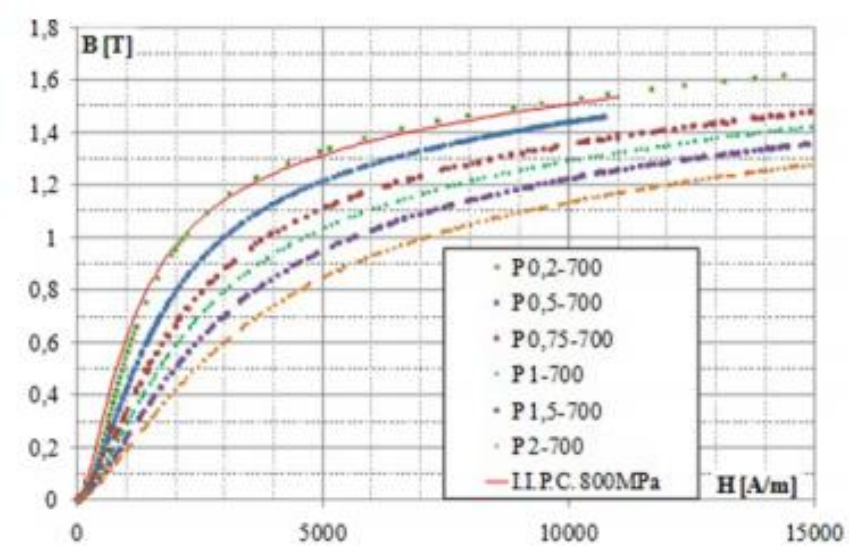

a)

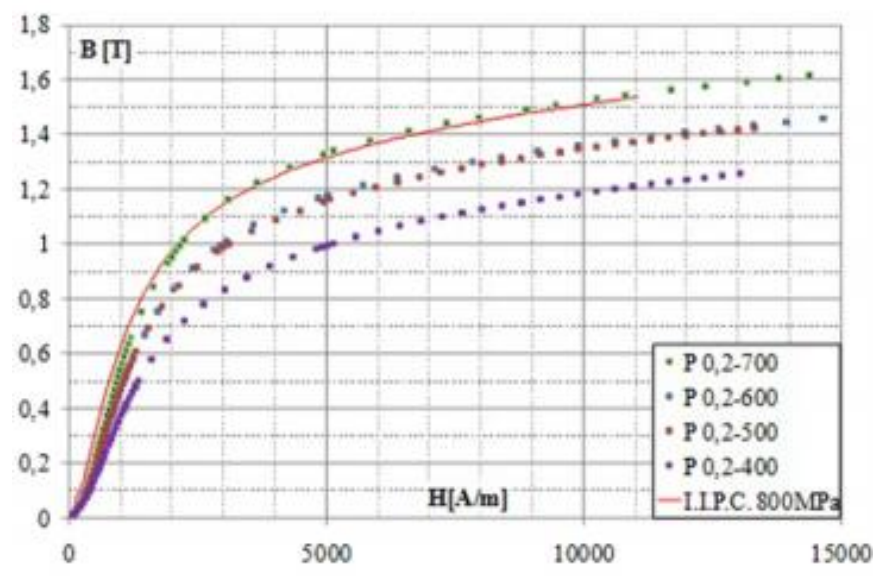

b)

Figure 14. Magnetic properties for: (a) different binder percentage at $700 \mathrm{MPa}$ compacting pressure and specific (b) binder material pressures of 0.2 percent [67]

\subsection{Cooling methods}

High speed Permanent Magnet Synchronous Motor (HSPMSM) has high power density and low strength but this results in density loss and higher rise in temperature [73]. HSPMSM poses problems with high rotor pressure and rising temperatures. Thermal analysis and refrigeration methods would be useful in increasing the life span of machines. Therefore, in order to determine thermal pressures, thermal convection and heating of the cooling fluid must be tested. The voltage unbalance produces negative sequence voltage in the air gap which rotates flux against the rotation of the rotor, helping to produce high currents resulting in increased temperature.

San Andres et al. [74] found that the torque constant decreases as the working temperature increases, resulting in a higher consumption of current. In addition, winding resistance increases with the temperature, resulting in high losses and lower efficiency. This temperature increases of the permanent neodymium-iron-boron (NdFeB) magnets causes the remanence flux density of $\mathrm{NdFeB}$ magnet to decrease, thus reducing the performance of electrical machines. In addition, high temperatures would result in the permanent magnet material being demagnetized irreversibly. In addition, the temperature gradient induced high temperature stress on the winding of the stator degrades winding insulation. This induces thermal aging and isolation aging at a faster rate [75]. Thermal design is as important as electromagnetic design for electrical machines, since the thermal rise of the electrical machine ultimately determines the output power of the electrical machines [76]. Winding insulation and permanent magnets play a critical role in enhancing the service life and performance of PMSMs.

Zhang et al. [77] explored the use of either sintered NdFeBs or SmCo for high performance applications by PM motor. Due to higher residual flux density and persuasive power, $\mathrm{NdFeB}$ permanent magnets are affected by temperature. The maximum endurable temperature of $\mathrm{NdFeB}$ permanent magnet is about $220^{\circ} \mathrm{C}$, and the permissible tensile strength is 120MPa. The permanent SmCo magnets have lower coercive strength and residual flux density, but unlike NdFeb PMs they are less affected by temperature. The permanent SmCo magnets have lower coercive power and residual flux density, but they are temperature-influenced to a lower extent in comparison to NdFeb PMs.

Hruska et al. [78] used heat sensors to map temperatures at different parts of the electric motor. Figure 15 provides a thermal map. Research has shown that as the permanent magnet temperature exceeds $220^{\circ} \mathrm{C}$, the losses are remarkable. Temperature of the winding under such conditions will be around $150^{\circ} \mathrm{C}$, which is less compared to the former. The hottest part of the chassis is located in its middle where the temperature results to be $105^{\circ} \mathrm{C}$. The critical parts of the machine are its bearings and temperature there is around 75$85^{\circ} \mathrm{C}$.

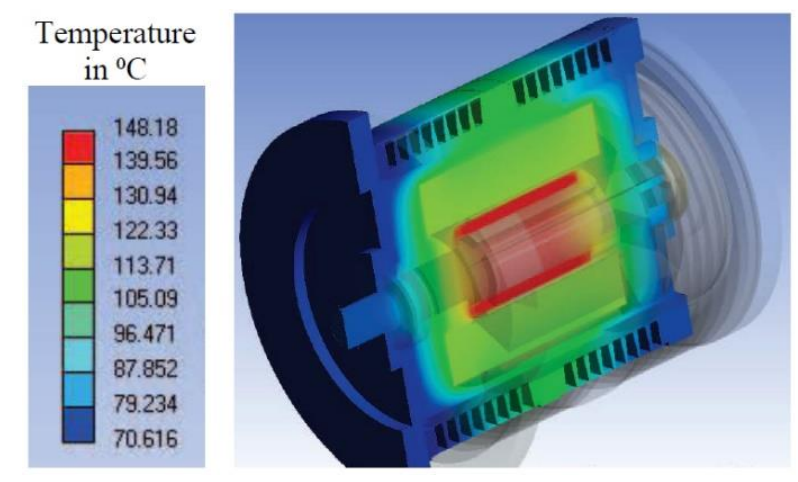

Figure 15. Temperature mapping on the cross section of the machine using Ansys [78]

Tosetti et al. [79] performed a heat transfer test in a model of a surface-mounted permanent magnet generator integrated with an air cooler, whose schematic is shown in Figure 16. A large amount of air flows unconventionally through the turbofan engine axially through the air gap of the unit. A complete fluid-thermal analysis was used to analyze the flow and temperature fields within the machine as reported in Figure 17 to investigate the adopted cooling system. Thermal mapping takes place both inside and above the surfaces. Nategh et al. [80] performed a thermal study of Synchronous Reluctance Machines (PMaSRMs) aided by PermanentMagnet. The stator winding is based on the use of Partial FEA and Lumped Parameter Modeling. The stator slot is made of several elliptical copper and impregnation layers in the proposed thermal design. On a PMaSRM with a water-cooling jacket [81], the thermal design is tested experimentally using finite element analysis (FEA), computational fluid dynamics (CFD) and thermal analysis methods. Tong et al. [82] tested a fully enclosed axial ventilation system (AVS) for permanent 
magnet synchronous machines (PMSMs) with self-circulation (TESC). Forced method of air cooling was used using external fans, such as radial flux PMSMs [83-85]. The cooling system was designed to ensure thorough cooling of critical parts having electrical devices, stator windings, stator heart, and the PMs. The temperature change in windings with forced air cooling versus the total volume flow rate is reported in Figure 18 [82].

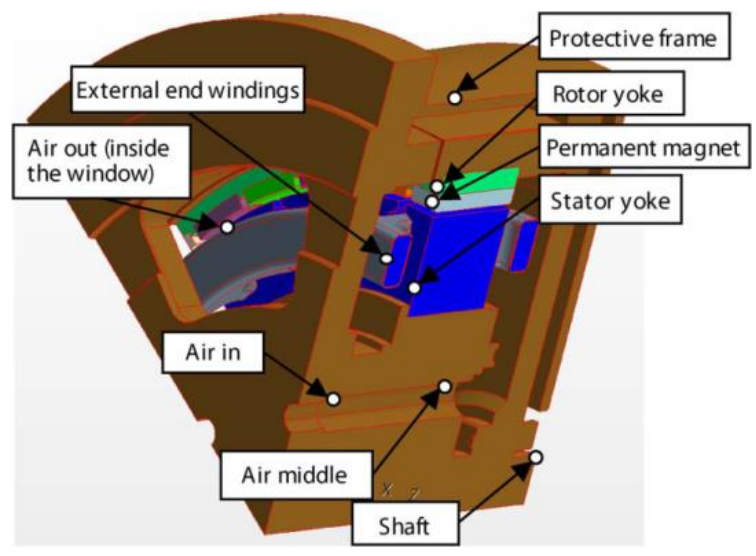

Figure 16. A schematic diagram of a permanent magnet electric machine[79]

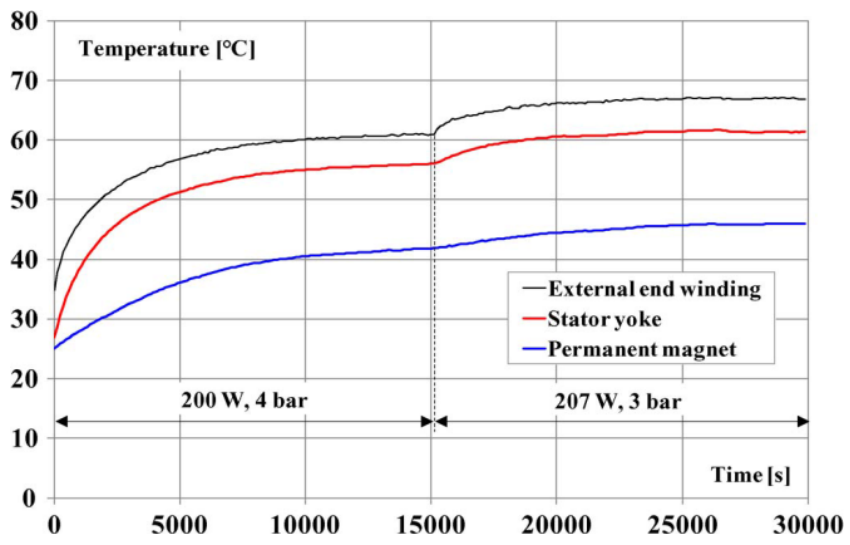

Figure 17. Measured external winding temperatures, stator yokes, and PM during the thermal locked-rotor test with a dc supply [79]

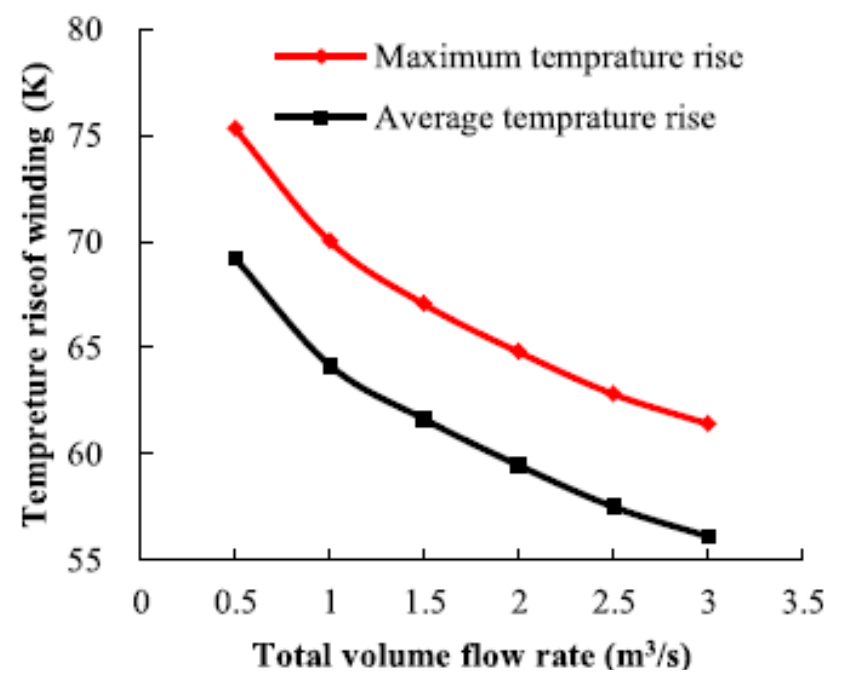

Figure 18. Temperature change in windings with forced air cooling [82]
Bailey et al. [86] designed generators and high-speed directconnected permanent-magnet engines for the petrochemical industry. To identify topologies of the cooling system, a lumped-parameter model was used to model the geometry of the machine including stator, rotor and cooling jacket. To predict the operating conditions of the machine, they used a computer-fluid dynamic model of the system. The engine losses are reported in Table 2. For structural integrity, the press fitted aluminum cooling jacket was heated by means of a water / glycol cooling current. Without being choked by the air gap size, heat was removed from the end turns. As a thermal insulator, carbon fibers jacket, water / glycol mixture flows through the air gap, supplying ventilation to both the rotor and the tips of the stator tooth.

Table 2. Losses under 5000 rpm operation [86]

\begin{tabular}{cccccc}
\hline & $\begin{array}{c}\text { Iron } \\
\text { Loss } \\
{[\mathbf{k W}]}\end{array}$ & $\begin{array}{c}\text { Slot Cu } \\
\text { Loss } \\
{[\mathbf{k W}]}\end{array}$ & $\begin{array}{c}\text { End-turn } \\
\text { Cu Loss } \\
{[\mathbf{k W}]}\end{array}$ & $\begin{array}{c}\text { Wind } \\
\text { age } \\
{[\mathbf{k W}]}\end{array}$ & $\begin{array}{c}\text { Total } \\
\text { Loss } \\
{[\mathbf{k W}]}\end{array}$ \\
\hline $\begin{array}{c}\text { No-Load } \\
\text { 3MW }\end{array}$ & 29.9 & 16.8 & 0.0 & 16.3 & 63.0 \\
Generating & 33.6 & 21.2 & 1.8 & 17.8 & 74.4 \\
\hline
\end{tabular}

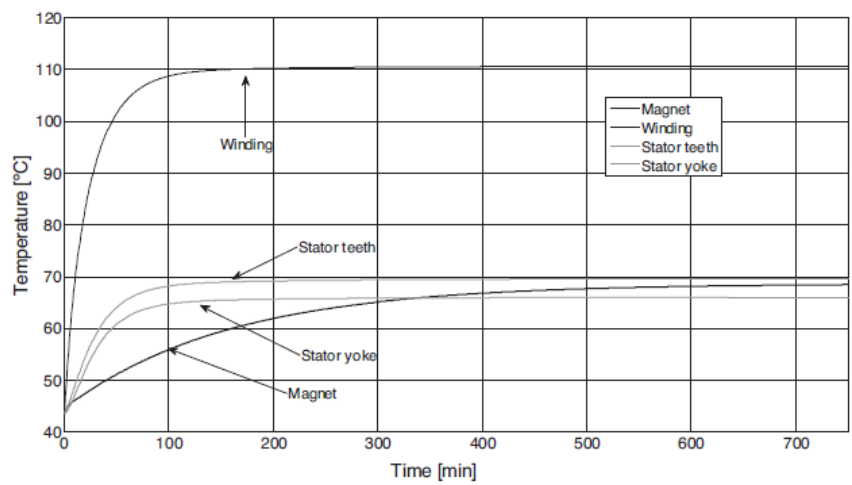

Figure 19. Temperatures at various components of electrical machine under normal speed and load at $40^{\circ} \mathrm{C}$ [88]

Ismagilov et al. [87] created a high-speed 5-kW PM generator for applications in aerospace for design, optimization and initial testing. The use of only air-cooling and failure of the liquid cooling system are the draw backs in the design. Nerg et al. [88] presented a double-radial-cooled low-speed high-torque PMSG analytical thermal model. A double radial cooling of a synchronous generator of $3.35 \mathrm{MW}$, $16 \mathrm{~Hz}$, was examined and the results are shown in Figure 19. The fans kept on the outside of the generator blast the cool air into the cooling channel in the double radial cooling, where the current is separated into several axial cooling channels. This is to minimize the length of one flow path of cool air and the rise of cool air temperature. The temperature of the stator windings decreases rapidly. The temperatures of the stator teeth and the stator yokes increase after the blower is stopped as shown in Figure 20. This is due to the fact that heat from the windings flows to the stator yokes and finally to the generator frame through the stator teeth. Results show that the temperature of the magnet should be below $70^{\circ} \mathrm{C}$, the average temperature of the stator should be below $120^{\circ} \mathrm{C}$. In the stator windings, the measured hot spot temperatures were $127^{\circ} \mathrm{C}$ and $85.6^{\circ} \mathrm{C}$ in the rotor magnets. 


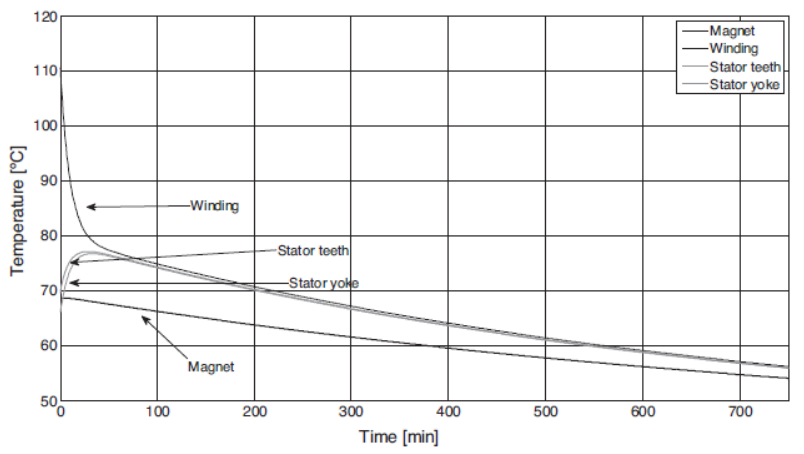

Figure 20. Temperatures of various components of electrical machine after stopping the blower [88]

Li et al. [89] engineered an HTS PM Engine with superconducting winding armature. Most superconducting motors with high temperatures utilize superconducting magnets as rotor poles to provide high magnetic flux density. HTS motors have a high density of energy and are used in various fields such as thruster systems and wind power systems. The high-flux density superconductive magnets influence the critical current of the superconductive tapes. To remove the effect, the temperature of the superconducting magnets must drop to $20 \mathrm{~K}-30 \mathrm{~K}$. Using the high-temperature superconductive tapes, the cooling costs are reduced. Using cold liquid nitrogen, the superconductive coils are cooled to 70K. To provide the cooling ability, two cryogenic refrigerators are used. When these refrigerators operate with full load, the minimum output will exceed 93.5 percent. Nollau et al. [90] present thermal optimization for the application of hybrid drives to improve cooling with flux barriers in the PMSM stator for traction motors. In this, the cooling jacket covering the stator, and there is no plate between the flux barriers and water jacket. A thin aluminum sheet separates the flux barriers from the gap to ensure that no fluid flows into the gap that causes short circuit. With turbulent flow, the flux barrier cooling is increased by 10 percent, resulting in higher heat dissipation as the cooling area is enhanced. Nollau et al. [91] developed in 2013, a new solution for traction engines in Battery Electric Vehicle (BEV) or hybrid drives. The new approach to cooling technique is based on a vortex pipe which produces an air stream of $-40^{\circ} \mathrm{C}$ and compares results using a standard method of water cooling. A transient thermal analysis carried out determines the distribution of temperature over a period. Table 3 shows the material data applied to different components, where $\mathrm{k}$ is the thermal conductivity, $\mathrm{c}_{\mathrm{p}}$ is the specific heat capacity and $\rho$ is the density.

The power losses are estimated using methods from finite element or analytically. Table 4 indicates the power losses in different parts of the electrical system for different operating conditions.

Table 3. Thermal data of used material [91]

\begin{tabular}{cccc}
\hline Material & $\mathbf{K}(\mathbf{W} / \mathbf{m} * \mathbf{K})$ & $\mathbf{C}_{\mathbf{p}}(\mathbf{J} /(\mathbf{k g} * \mathbf{K})$ & $\mathbf{P}\left(\mathbf{k g} / \mathbf{m}^{\mathbf{3}}\right)$ \\
\hline Iron & 50 & 450 & 7860 \\
Copper & 370 & 385 & 8960 \\
Aluminium & 210 & 896 & 2707 \\
NdFeb & 9 & 370 & 7500 \\
magnet & & & \\
Slot & 0.25 & 2.2 & 2000 \\
insulation & & 1013 & 0.013 \\
Air & 0.028 & 4.12 & 1000 \\
Water & 0.60 & &
\end{tabular}

Table 4. Power losses in different parts of the electrical machine [91]

\begin{tabular}{ccc}
\hline Losses & 3000 (rpm) & 8000(rpm) \\
\hline Pcopper $_{\text {cW }}[\mathrm{W}$ & 3552 & 3552 \\
PIron_Stator[W] & 538.95 & 2697.05 \\
PIron_Rotor $[\mathrm{W}]_{\text {I }}$ & 103.05 & 475.95 \\
Pmagnet $\left._{\text {m }}\right]$ & 10.3 & 47.5 \\
\hline
\end{tabular}

Hingane et al. [92] optimized electrical requirements and produced at the minimum possible weight a high-power magnet DC motor. Requirements: $4.8 \mathrm{~kg}$ engine weight, $48 \mathrm{~V}$ voltage, 7A current, $6140 \mathrm{rpm}$ speed and $45 \mathrm{~N}$-m deceleration torque. The power to weight ratio is high and the duty cycle is low, since enough thermal mass is not available for heat dissipation. External cooling may help to increase the efficiency. The DHX Falcon electric motor [93] is made from standard materials; steels and magnets. DHX Falcon $80 \mathrm{hp}$ $(60 \mathrm{~kW})$ weighs $30 \mathrm{lbs}(13.6 \mathrm{~kg})$ with an efficiency of 96 percent. Power densities of $120 \mathrm{HP}$ per gallon $(25 \mathrm{~kW}$ per liter) and $195 \mathrm{ft} /$ gallon $(70 \mathrm{Nm} / \mathrm{l})$ and exceptional torque are possible. Due to resistance and friction between rotating parts, high-torque electrical motors produce thermal losses in windings. This heat usually dissipates via air or liquid cooling to the frame through the stator. A Direct-Winding Heat Exchanger (DWHX) is used by the DHX Falcon motor. It uses micro-feature enhanced heat exchangers to reduce the length of conduction from windings to the setting. For decreased thermal resistance and increased efficiency, each DWHX features small channels to dissipate heat. Figure 21 displays a comparison of the size of a small electric motor.

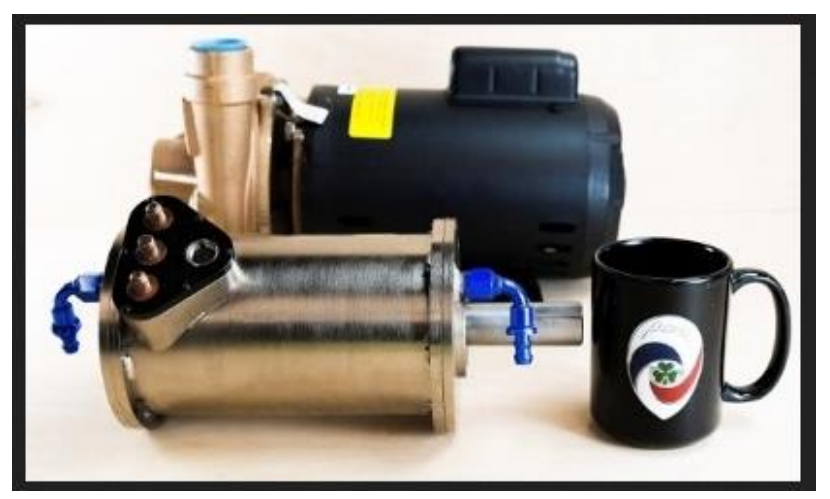

Figure 21. 80-hp DHX Falcon electric motor (front) compared to a standard 1.5-hp electric motor and coffee mug. 80-hp DHX Falcon electric motor (front) vs traditional 1.5-hp electric motor and coffee mug [93]

\section{CONCLUSIONS}

This paper has drawn a general review on the techniques to reduce weight and to increase the efficiency of the electric motors using lightweight materials, novel manufacturing processes, magnetic materials and cooling methods. Electric motors, especially in automotive applications, represent more and more the technology of the future. Therefore, even if there is still a long way to go, the hope of the authors is that this becomes an increasingly consolidated technology and that the Enhanced Efficiency Electric Motors can constitute an answer to the problems connected to energy saving. 


\section{ACKNOWLEDGEMENT}

Thanks to all the co-authors and the team for the cooperation and for the work done. Thanks to Prof. Enrico Lorenzini, Editor in Chief of ACSM, for the speed of the editorial process and for the support given to the corresponding author.

\section{REFERENCES}

[1] World Bank Open Data - Electric power consumption (kWh per capita). Available online: https://data.worldbank.org/indicator/EG.USE.ELEC.KH .PC, accessed on 22 October 2019.

[2] Chen, Z.M., Chen, G.Q. (2011). An overview of energy consumption of the globalized world economy. Energy Policy, 39(10): 5920-5928. https://doi.org/10.1016/j.enpol.2011.06.046

[3] Commission, T.H.E., The, O.F., Communities, E. (2009). Commission Regulation (EC) 640/2009 Implementing Directive 2005/32/EC of the European Parliament and of the Council with regard to eco-design requirements for electric motors. Official Journal of the European Union, 640: L 191/26. https://eurlex.europa.eu/LexUriServ/LexUriServ.do?uri=OJ:L:200 9:191:0026:0034:EN:PDF, accessed on 2 March, 2020.

[4] European Commission (2005). Directive 2005/32/EC of the European Parliament and of the Council of 6 July 2005 establishing a framework for the setting of ecodesign requirements for energy-using products and amending Council Directive 92/42/EEC and Directives 96/57/EC and 2000/55/EC. Official Journal of the European Union, 191(1600): 1-30.

[5] Pitis, C.D., Design, E.M. (2014). Designing Energy Efficiency Electric Motors (EEEM) by using Reliability Indicators.

[6] Shokrollahi, H., Janghorban, K. (2007). Soft magnetic composite materials (SMCs). Journal of Materials Processing Technology, 189(1-3): 1-12. https://doi.org/10.1016/j.jmatprotec.2007.02.034

[7] Guo, Y.G., Zhu, J.G., Wu, W. (2005). Thermal analysis of soft magnetic composite motors using a hybrid model with distributed heat sources. IEEE Transactions on Magnetics, TMAG, 41(6): 2124-2128. https://doi.org/10.1109/TMAG.2005.848316

[8] Chan, C.C. (2007). The state of the art of electric, hybrid, and fuel cell vehicles. Proceedings of the IEEE, JPROC, 95(4):

704-718.

https://doi.org/10.1109/JPROC.2007.892489

[9] Jahns, T.M., Blasko, V. (2001). Recent advances in power electronics technology for industrial and traction machine drives. Proceedings of the IEEE, 89(6): 963-975. https://doi.org/10.1109/5.931496

[10] Wang, T., Zhang, Q, Cheng, S. (2004). Design characteristics of the induction motor used for hybrid electric vehicle. 12th Symposium on Electromagnetic Launch https://doi.org/10.1109/TMAG.2004.838967

[11] Pugsley, G., Fonseca, A., Bul Van A.L. (2003). New modelling methodology for induction machine efficiency mapping for hybrid vehicles. IEMDC 2003 - IEEE International Electric Machines and Drives Conference, IEMDC. https://doi.org/10.1109/IEMDC.2003.1210324
[12] Cho, D.H., Jung, H.K., Lee, C.G. (2001). Induction motor design for electric vehicle using a niching genetic algorithm. IEEE Transactions on Industry Applications, TIA. https://doi.org/10.1109/28.936389

[13] Benbouzid, M.E.H., Nait Said, N.S. (1998). An efficiency-Optimization controller for induction motor drives. IEEE Power Engineering Review, PER. https://doi.org/10.1109/39.666569

[14] Zidani, F., Benbouzid, M.E.H., Diallo, D. (2000). Fuzzy efficient-optimization controller for induction motor drives. IEEE Power Engineering Review, PER, 20(10): 43-44. https://doi.org/10.1109/39.876882

[15] Lee, H.D., Sul, S.K. (1998). Fuzzy-logic-based torque control strategy for parallel-type hybrid electric vehicle. IEEE Transactions on Industrial Electronics, TIE. https://doi.org/10.1109/41.704891

[16] Kou, B.Q., Yi, L.L., Meng, F. (2004). Operating control of efficiently generating of induction motor for driving hybrid electric vehicle (HEV). 12th Symposium on Electromagnetic Launch Technology. https://doi.org/10.1109/TMAG.2004.838980

[17] Brusaglino, G., Ravello, V., Schofield, N., Howe, D. (1999). Advanced drives for electrically propelled vehicles. IEE Colloquium (Digest).

[18] Jiang, S.Z., Chau, K.T., Chan, C.C. (2003). Spectral analysis of a new six-phase pole-changing induction motor drive for electric vehicles. IEEE Transactions on Industrial Electronics, TIE. https://doi.org/10.1109/TIE.2002.807662

[19] Tai, Y., Liu, Z. (2010). Analysis on three-dimensional transient temperature field of induction motor. Electric Power Industry. Proceedings of the CSEE, ISSN: 02588013.

[20] Dokopoulos, Xypteras. (1982). Analysis of transient temperature distribution in a rotating machine. Electrical Machines.

[21] Jiang, W., Jahns, T.M. (2015). Coupled ElectromagneticThermal Analysis of Electric Machines Including Transient Operation Based on Finite Element Techniques. IEEE Tran. on Industry Applications, TIA. https://doi.org/10.1109/TIA.2014.2345955

[22] Xie, Y., Guo, J., Cheng, P., Li, Z. (2018). Coupled fluidthermal analysis for induction motors with broken bars operating under rated load. Energies, 11(8). https://doi.org/10.3390/en11082024

[23] Nogay, H.S. (2011). Prediction of internal temperature in stator winding of three-phase induction motors with ann. European Transactions on Electrical Power, ETWP. https://doi.org/10.1002/etep.420

[24] Arbab, N., Wang, W., Isfahani, A., Fahimi, B. (2014). Temperature effects on steady state performance of an induction machine and a switched reluctance machine. IEEE Transportation Electrification Conference and Expo: Components, Systems, and Power Electronics From Technology to Business and Public Policy, ITEC 2014. https://doi.org/10.1109/itec.2014.6861826

[25] Arbab, N., Wang, W., Lin, C., Hearron, J. (2015). Thermal modelling and analysis of a double-stator switched reluctance motor. IEEE Transactions on Energy Conversion,

TEC. https://doi.org/10.1109/TEC.2015.2424400

[26] Zhou, K. (2015). Computationally Efficient finite Element Based Thermal and Electromagnetic Models of Electric machines. A dissertation submitted in partial 
fulfilment of the requirements for the degree of Doctor of Philosophy (Electrical Engineering: Systems) in the University of Michigan.

[27] Hashemnia, N., Asaei, B. (2008). Comparative study of using different electric motors in the electric vehicles. Proceedings of the 2008 International Conference on Electrical Machines, ICEM'08. Computationally Efficient finite Element Based Thermal and Electromagnetic Models of Electric Machines. https://doi.org/10.1109/ICELMACH.2008.4800157

[28] Mitra, A., Emadi, A. (2012). On the suitability of large switched reluctance machines for propulsion applications. IEEE Transportation Electrification Conference and Expo, ITEC 2012. https://doi.org/10.1109/ITEC.2012.6243423

[29] Wang, W., Fahimi, B. (2012). Comparative study of electric drives for EV/HEV propulsion system. Elec. Sys. for Aircraft, Railway and Ship Propulsion, pp. 1-6. https://doi.org/10.1109/ESARS.2012.6387497

[30] Rahman, Z., Ehsani, M., Butler, K.L. (2000). An investigation of electric motor drive characteristics for EV and HEV propulsion systems. SAE Technical Papers. https://doi.org/10.4271/2000-01-3062

[31] Chan, C.C., Chau, K.T. (2001). Modern electric vehicle technology. Oxford University Press on Demand, 47.

[32] Lorenz, R.D. (1999). Advances in electric drive control. IEEE International Electric Machines and Drives Conference, IEMDC 1999 - Proceedings. https://doi.org/10.1109/IEMDC.1999.768671

[33] Chan, C.C., Chau, K.T. (1997). An overview of power electronics in electric vehicles. IEEE Transactions on Industrial Electronics, TIE. https://doi.org/10.1109/41.557493

[34] Zeraoulia, M., Benbouzid, M.E.H., Diallo, D. (2006). Electric motor drive selection issues for HEV propulsion systems: A comparative study. IEEE Transactions on Vehicular Technology,

TVT. https://doi.org/10.1109/TVT.2006.878719

[35] Franke, J., Kreitlein, S., Guenther, S. (2013). Energyefficient production strategies and technologies for electric drives. Proceedings of the IEEE Intl. Conference on Industrial Technology. ICIT. https://doi.org/10.1109/ICIT.2013.6505967

[36] De Keyser, H. (2019). Lightweighting powertrains in the electric future. Available online: http://www.jeccomposites.com/knowledge/international -composites-news/lightweighting-powertrains-electricfuture, accessed on 28 October 2019.

[37] Efficient lightweight motors for electric vehicles by Karlsruhe Institute of Technology July 22, 2013, KIT University of the State of Baden-Wuerttemberg and National Research Center of the Helmholtz Association.

[38] Koch, S.F., Peter, M., Fleischer, J. (2017). Lightweight design and manufacturing of composites for highperformance electric motors. Procedia CIRP, 66: $283-$ 288. https://doi.org/10.1016/j.procir.2017.03.274

[39] Fraunhofer Institute for Chemical Technology (2019). Directly-cooled electric motor made from polymer materials. Available online: https://www.fraunhofer.de/en/press/researchnews/2019/february/directly-cooled-electric-motormade-from-polymer-materials.html, accessed on 31 October 2019.

[40] Prolemo, U. (2013). Efficient lightweight motors for electric vehicles (July): 1-2. Available online: https://phys.org/news/2013-07-efficient-lightweightmotors-electric-vehicles.html, accessed on 24 October 2019.

[41] Available online: https://www.technicaltextile.net/news/amcs-reduceweight-of-electric-motors-alvant-project-247331.html, accessed on 26 October 2019.

[42] Ginger Gardiner. Composites World, Available online: https://www.compositesworld.com/news/reducing-heatin-ev-motors-via-fiber-reinforced-thermoset-housingand-stator, accessed on 14 October 2019.

[43] Thermally conductive, fibre-reinforced plastic for electric motor housings and method for the production and use thereof. Available online: https://patents.google.com/patent/WO2015043814A2/e n, accessed on 12 October 2019.

[44] Composite fiber wheel with integrated motor. Available online: https://www.lbf.fraunhofer.de/en/projectsproducts/carbon-fiber-reinforced-polymer-wheel.html, accessed on 10 October 2019.

[45] Peter, M., Fleischer, J. (2013). New conceptual lightweight design approaches for integrated manufacturing processes: Influence of alternative materials on the process chain of electric motor manufacturing. 3rd International Electric Drives Production Con., EDPC 2013 - Proc. https://doi.org/10.1109/EDPC.2013.6689735

[46] Misra, A.K. (2014). Nano-Magnets and Additive Manufacturing for Electric Motors. 8th Annual Comparative Aircraft Flight Efficiency Electric Aircraft Symposium (EAS VIII), April 25- 26, 2014 in Santa Rosa, California.

[47] Blain, L. (2018). Magnax prepares to manufacture radically high-powered, compact axial flux electric motor. Available online: https://newatlas.com/magnaxaxial-flux-electric-motor/54821/, accessed on 18 October 2019.

[48] Henke, M., Narjes, G., Hoffmann, J. (2018). Challenges and opportunities of very light high-performance electric drives for aviation. Energies, 11(2): 344. https://doi.org/10.3390/en11020344

[49] De Leon, A.C., Rodier, B., Bajamundi, C. (2018). Plastic metal-free electric motor by 3D printing of graphenepolyamide powder. ACS Applied Energy Materials, 1(4): 1726-1733. https://doi.org/10.1021/acsaem.8b00240.

[50] Zhang, J., Spath, D., Boronka, A., He, Y. (2018). Costefficient selection of manufacturing technologies for an electric traction motor shaft produced in China. Procedia CIRP. https://doi.org/10.1016/j.procir.2018.03.206

[51] Chai, S.H., Lee, B.H., Hong, J.P. (2012). Weight reduction design of in-wheel type motor for power density improvement. World Electric Vehicle Journal, WEVJ. https://doi.org/10.3390/wevj5020550

[52] Ruff, B., Li, W., Venkatasubramanian, R. (2013). Development of lightweight sustainable electric motors. Nanotube Superfiber Materials: Changing Engineering Design, 21: 595-626. https://doi.org/10.1016/B978-14557-7863-8.00021-9

[53] Patent: A composite rotor and stator for an electric motor. Available on line: https://patents.google.com/patent/US6150747A/en, accessed on 8 October 2019.

[54] Yusuf, B. (2018). Revolutionary fully 3D Printed electric 
motor is the World first. Available online: https://all3dp.com/3d-printed-electric-motor/, accessed on 6 October 2019.

[55] Karthik, D.E., Mrudunayani, P., Babu, S.V.V.K. (2019). Influence of magnetic water on self-compacting concrete using sulphate resisting cement influence of magnetic water on self-compacting concrete using sulphate resisting cement. Annales de Chimie - Science des Matériaux, 43(5): 347-352. https://doi.org/10.18280/acsm.430511

[56] Alam, M.F., Bora, M., Sharma, B., Barman, R.N. (2019). Numerical investigation of magneto-hydrodynamics mixed convection in a square cavity for various shaped conducting obstacles placed at the center numerical investigation of magneto-hydrodynamics mixed convection in a square cavity for various shaped conducting obstacles placed at the center. Mathematical Modelling of Engineering Problems, 6(4): 550-556. https://doi.org/10.18280/mmep.060410

[57] Aprea, C., Greco, A., Maiorino, A., Masselli, C. (2017). A comparison between electrocaloric and magnetocaloric materials for solid state refrigeration. International Journal of Heat and Technology, 35(1): 225-234. https://doi.org/10.18280/ijht.350130

[58] Aprea, C., Greco, A., Maiorino, A., Masselli, C. (2017). Analyzing the energetic performances of AMR regenerator working with different magnetocaloric materials: Investigations and viewpoints. International Journal of Heat and Technology, 35: S383-S390. https://doi.org/10.18280/ijht.35Sp0152

[59] Greco, A., Aprea, C., Maiorino, A., Masselli, C. (2019). On the utilization of nanofluids as secondary fluid for heat transfer in a magnetocaloric cooler. Tecnica Italiana Italian Journal of Engineering Science, 63(1): 52-58. https://doi.org/10.18280/ti-ijes.630107

[60] Guo, Y.G., Zhu, J.G. (2006). Applications of soft magnetic composite materials in electrical machines: A review. Australian J1. of Electrical and Electronics Engineering,

AJEEE https://doi.org/10.1080/1448837X.2006. 11464143

[61] Kordecki, A., Weglinski, B. (1990). Development and applications of soft magnetic PM materials. Powder Metallurgy, PM, Taylor \& Francis, 33(2): 151-155. https://doi.org/10.1179/pom.1990.33.2.151

[62] Jansson, P. (1992). Soft magnetic materials for AC applications. Powder Metallurgy, 35(1): 63-66.

[63] Hamler, A., Gorican, V., Sustarsic, B., Sirc, A. (2006). The use of soft magnetic composite materials in synchronous electric motor. Journal of Magnetism and Magnetic Materials, 304(2): e816-e819. https://doi.org/10.1016/j.jmmm.2006.03.003

[64] Widmer, J.D., Martin, R., Kimiabeigi, M. (2015). Electric vehicle traction motors without rare earth magnets. Sustainable Materials and Technologies, JSusmat, 3:

7-13. https://doi.org/10.1016/j.susmat.2015.02.001

[65] De Gennaro, M., Jurgens, J., Zanon, A. (2019). Designing, prototyping and testing of a ferrite permanent magnet assisted synchronous reluctance machine for hybrid and electric vehicles applications. Sustainable Energy Tech and Assessment, SETA. https://doi.org/10.1016/j.seta.2018. 12.002

[66] Mikami, H., Ide, K., Shimizu, Y., Senoo, M., Seki, H. (2011). Historical evolution of motor technology, Hitachi
Review

[67] Ferraris, L., Pošković, E., Franchini, F. (2016). New soft magnetic composites for electromagnetic applications with improved mechanical properties. AIP Advances. https://doi.org/10.1063/1.4943413

[68] Ferraris, L., Franchini, F., Poskovic, E. (2016). Hybrid magnetic composite (HMC) materials for sensor applications. 2016 IEEE Sensors Applications Symposium (SAS), Catania, Italy. https://doi.org/10.1109/SAS.2016.7479833

[69] Xing, Q., Miller M., Zhou, L., Dillon, H. (2013). Phase and elemental distributions in alnico magnetic materials. IEEE Tran. on Magnetics, 49(7): 3314-3317. https://doi.org/10.1109/TMAG.2013.2252155

[70] Ferraris, L., Poskovic, E., Franchini, F. (2018). Study of the compositions of Hybrid Magnetic Composite (HMC) materials for sensor applications. 20th European Conference on Power Electronics and Applications, EPE 2018 ECCE Europe.

[71] Pošković, E., Ferraris, L., Franchini, F., Grande, M. (2019). The effect of particle size on the core losses of soft magnetic composites. AIP Advances, 9(3). https://doi.org/10.1063/1.5080079

[72] Soft magnetic composites - enabling more efficient electromagnetic designs. Available online: https://www.hoganas.com/en/powder-technologies/softmagnetic-composites/, accessed on 19 October 2019.

[73] Wang, J.Q., Wang, F.X. (2011). Thermal analysis and test for a high speed PM motor for fan application. Advanced Materials Research, AMR, 383: 4727-4734. Available online: https://www.scientific.net/AMR.383390.4727, accessed on 22 October 2019.

[74] Sanandres, U., Almandoz, G., Poza, J., Ulgaide, G. (2014). Design of cooling systems using computational fluid dynamics and analytical thermal models. IEEE Transactions on Industrial Electronics, TIE. https://doi.org/10.1109/TIE.2013.2286081

[75] Slemon, G.R. (1993). On the design of high-performance surface-mounted PM motors. IEEE Transactions on Industry Applications, https://doi.org/10.1109/28.273631

[76] Nerg, J., Rilla, M., Pyrhönen, J. (2008). Thermal analysis of radial-flux electrical machines with a high power density. IEEE Transactions on Industrial Electronics, TIE. https://doi.org/10.1109/TIE.2008.927403

[77] Zhang, F., Hao, Y., Liu, G., Qiu, F. (2016), Design and analysis of $100 \mathrm{~kW}$ high speed permanent magnet synchronous motor. IEEE Transportation Electrification Conference and Expo, Asia-Pacific (ITEC Asia-Pacific), pp. 843-847. https://doi.org/10.1109/ITECAP.2016.7513066

[78] Hruska, K., Kindi, V., Komrska, T., Pechenek, R., Streit, L. (2016). Concept and design of a special purpose permanent magnet synchronous motor. ELEKTRO 2016 - 11th Intl Conf., Proceedings, pp. 156-161. https://doi.org/10.1109/ELEKTRO.2016.7512056

[79] Tosetti, M., Maggiore, P., Cavagnino, A., Vaschetto, S. (2014). Conjugate heat transfer analysis of integrated brushless generators for more electric engines. IEEE Transactions on Industry Applications, TIA. https://doi.org/10.1109/TIA.2013.2296657

[80] Nategh, S., Wallmark, O., Leksell, M., Zhao, S. (2012). Thermal analysis of a PMaSRM using partial FEA and lumped parameter modeling. IEEE Transactions on 
Energy

Conversion,

TEC.

https://doi.org/10.1109/TEC.2012.2188295

[81] Boglietti, A., Cavagnino, A., Staton, D., Shanel, M., Mueller, M. (2009). Evolution and modern approaches for thermal analysis of electrical machines. IEEE Transactions on Industrial Electronics, TIE. https://doi.org/10.1109/TIE.2008.2011622

[82] Tong, W., Wu, S., Tang, R. (2018). Totally Enclosed Self-Circulation Axial Ventilation System Design and Thermal Analysis of a 1.65-MW Direct-Drive PMSM. IEEE Transactions on Industrial Electronics, TIE. https://doi.org/10.1109/TIE.2018.2823698

[83] Ruuskanen, V., Nerg, J., Niemela, M., Pyrhonen, J. (2013). Effect of radial cooling ducts on the electromagnetic performance of the permanent magnet synchronous generators with double radial forced air cooling for direct-driven wind turbines. IEEE Transactions on Magnetics, TMAG. https://doi.org/10.1109/TMAG.2013.2238679

[84] Fan, X., Qu, R., Zhang, B., Li, J. (2017). Ventilation and thermal improvement of radial forced air-cooled FSCW permanent magnet synchronous wind generators. IEEE Transactions on Industry Applications, TIA. https://doi.org/10.1109/TIA.2017.2686350

[85] Nerg, J., Ruuskanen, V. (2011). Lumped Parameter Based Thermal Analysis of a Direct Driven Permanent Magnet Wind Generator Utilizing Double Radial Air Cooling, ELECTRIMACS, Cergy-Pontoise, France.

[86] Bailey, C., Saban, D.M., Guedes-Pinto, P. (2009). Design of high-speed direct-connected permanentmagnet motors and generators for the petrochemical industry. IEEE Transactions on Industry Applications, TIA. https://doi.org/10.1109/TIA.2009.2018964

[87] Ismagilov, F.R., Vavilo, V., Miniyarov, A., Veselov, A., Ayguzina, V. (2017). Design, optimization and initial testing of a high-speed $5-\mathrm{kW}$ permanent magnet generator for aerospace application. Prog. In Electromagnetics Res., PIERC. https://doi.org/10.2528/PIERC 17091805

[88] Nerg, J., Ruuskanen, V. (2013). Lumped-parameterbased thermal analysis of a doubly radial forced-aircooled direct-driven permanent magnet wind generator.
Mathematics and Computers in Simulation, MATCOM. https://doi.org/10.1016/j.matcom.2012. 08.009

[89] Li, L., Cao, J., Kou, B., Han, Z., Chen, Q. (2012). Design of the HTS permanent magnet motor with superconducting armature winding. IEEE Tran. on Applied Superconductivity, TASC. Italian Journal of Engineering https://doi.org/10.1109/TASC.2011.2181293

[90] Nollau, A., Gerling, D. (2016). A flux barrier cooling for traction motors in hybrid drives. 2015 IEEE International Electric Machines \& Drives Conference (IEMDC), Coeur d'Alene, ID, USA. https://doi.org/10.1109/iemdc.2015.7409199

[91] Nollau, A., Gerling, D. (2013). A new cooling approach for traction motors in hybrid drives. Proceedings of the 2013 IEEE International Electric Machines and Drives Conference, IEMDC 2013. https://doi.org/10.1109/IEMDC.2013.6556136

[92] Hingane, A.S., Basarge, S., Kabule, P., Jagtap, O. (2018). Design and development of high power to weight ratio PMDC motor for short duty cycle. International Research Journal of Engineering and Technology, 5(5): 3135-3137.

[93] Pittman, K. (2016). Tiny Electric Motor Delivers 80 Horsepower. Available online: https://www.engineering.com/AdvancedManufacturing/ ArticleID/11406/Tiny-Electric-Motor-Delivers-80Horsepower.aspx, accessed on 31 October 2019.

\section{NOMENCLATURE}

$\begin{array}{ll}\text { W } & - \text { Watt } \\ \mathrm{kW} & - \text { kilo Watts } \\ \mathrm{MW} & - \text { Mega Watts } \\ \mathrm{M} & - \text { meter } \\ \mathrm{K} & - \text { Kelvin } \\ \mathrm{J} & - \text { Joule } \\ \mathrm{kg} & - \text { kilogram } \\ \mathrm{rpm} & - \text { revolutions per minute } \\ \mathrm{k} & - \text { Thermal conductivity, } \mathrm{W} / \mathrm{m} * \mathrm{~K} \\ \mathrm{Cp} & - \text { Specific heat capacity, } \mathrm{J} /(\mathrm{kg} * \mathrm{~K}) \\ \rho & - \text { density, } \mathrm{kg} / \mathrm{m}^{3}\end{array}$

